\title{
Identification of Mgenia fuscovaria (Stål) (Hemiptera: Cicadelli- dae), a Vector of Aster Yellows Disease on Grapevines in South Africa, and Differentiation from Mgenia angusta (Theron) by Nucleotide Sequences of the Mitochondrial Cytochrome Oxidase I (cox1) Gene
}

\author{
G. Pietersen*1,2, G. Pietersen Jnr ${ }^{1,2}$, I. Pietersen ${ }^{1,2}$, M. Stiller ${ }^{3}$ \\ (1) Department of Microbiology and Plant Pathology, University of Pretoria, Pretoria 0002, South Africa. \\ (2) Forestry and Agricultural Biotechnology Institute (FABI), University of Pretoria, Pretoria 0002, South Africa \\ (3) Agricultural Research Council, Plant Protection Research Institute, Private Bag X134, Queenswood, Pretoria 0121, South \\ Africa
}

Submitted for publication: July 2017

Accepted for publication: February 2018

Key words: Mgenia fuscovaria, aster yellows phytoplasma, leafhopper, grapevine, Vitis vinifera

\begin{abstract}
Aster yellows phytoplasma (AY), only recently reported in South Africa and still limited in its distribution in the country, causes a serious disease of grapevine. A leafhopper, Mgenia fuscovaria (Stål)(Hemiptera: Cicadellidae), was shown to transmit AY to grapevine (Vitis vinifera L.) locally. A second Mgenia species, identified as Mgenia angusta (Theron), has also been found in vineyards in South Africa but has not been shown to transmit AY. M. angusta is morphologically similar to M. fuscovaria, but does differ regarding the size of the male sex organ and in the number of teeth of the blades making up the ovipositor. In this study, we determined the nucleotide sequence of the mitochondrial cytochrome oxidase I gene (coxl), commonly used in insect bar-coding, of a number of specimens of males, females and nymphs of both M. fuscovaria and M. angusta. No differences were observed between the coxl sequences of the male, female and nymph specimens putatively assigned to any specific species, but some nucleotide sequence differences were observed between specimens of $M$. fuscovaria and M. angusta. These differences, however, were insufficient to allow the development of PCR systems specific to each species.
\end{abstract}

\section{INTRODUCTION}

A worldwide trend of loss in "classical" (morphological description) insect taxonomy expertise, along with an overwhelming number of potential insect species, requires an alternative approach to insect taxonomic identification. DNA sequence data is a potential remedy for this taxonomy crisis. The sequencing of the $5^{\prime}$ end of the cox 1 gene has become the most widely used approach (www.barcodinglife. org), as the mitochondrial DNA is highly abundant in the cell and its amplification is reliable; and coxl is often variable from populations to higher taxonomic levels (Hebert et al., 2003). Hebert et al. (2003) proposed using a 650 base-pair region of the cytochrome c oxidase subunit I (cox-1) gene as the universal barcode sequence in animals to enable the identification of species. Sequence variation in this region has been found to be highly structured and partitioned between discrete clusters that correspond broadly to specieslevel entities (Papadoupolou et al., 2008).
During a recent study (Krüger et al., 2011), a leafhopper identified as Mgenia fuscovaria (Stål)(Hemiptera: Cicadellidae) was shown to transmit "Candidatus Phytoplasma asteris (16Sr1-B group)", also called aster yellows phytoplasma (AY) to grapevine (Vitis vinifera L.). AY is an organism only recently reported in South Africa (Engelbrecht et al., 2010) and causes a serious disease of grapevine. In South Africa, the disease is restricted to only some grapevine-growing regions of the Western Cape and is a quarantine organism, with various control measures being enforced and delineating surveys being done regularly to restrict the area affected by the disease. Very little is known of the local epidemiology of the phytoplasma, or of the biology of the vector. In order to conduct epidemiological studies and controlled transmission experiments in which nymphs are included, unequivocal identification of the species involved is required. This fact was reinforced by the discovery of a second Mgenia spe- 
cies, identified as Mgenia angusta (Theron) (Theron, 1984), in vineyards during this study. The size of the male sex organ and the number of teeth found on one of the blades making up the ovipositor (valvula 2) in the case of females morphologically differentiated $M$. angusta from M. fuscovaria. However, these differences will be difficult to utilise when studying large numbers of specimens, or specimens from sticky traps. In this study we have determined the nucleotide sequence of the mitochondrial cytochrome oxidase I gene (cox 1), commonly used in insect bar-coding, of a number of specimens of both M. fuscovaria and M. angusta. The cox 1 sequences of males, females and nymphs of specimens putatively assigned to either $M$. fuscovaria or $M$. angusta were essentially identical within the species, with a number of minor, inconsistent single-nucleotide polymorphisms. However, a number of consistent nucleotide sequence differences were observed between sequences from $M$. fuscovaria and $M$. angusta specimens. Differences were insufficient to allow the development of standard PCR systems specific to each species. The cox 1 nucleotide sequences of both $M$. fuscovaria and $M$. angusta have been deposited with Genbank (accession numbers KP823217 and KP823218).

\section{MATERIALS AND METHODS Samples}

Putative Mgenia fuscovaria individuals were collected from various sites in the Western Cape. These were placed in 70\% ethanol, and the collection site, date and other collection data were recorded. The samples were identified at the Agricultural Research Council - Plant Protection Research Institute (ARC-PPRI) using gross morphological traits along with a detailed analysis of the genitalia (Nault \& Rodriguez, 1985). Morphogroups of putative $M$. fuscovaria adult females and nymphs were identified and individuals were stored separately in labelled tubes prior to DNA extraction, PCR and sequencing.

\section{Identification by morphology}

The morphology of, amongst other features, the male sex organ is used to distinguish species of leafhoppers. The last few segments of the abdomen of specimens were cut off and soaked in cold $\mathrm{KOH}$ until clear, and then examined under a stereo light microscope. The remainder of the specimen was stored for DNA extraction and PCR. The sex organ of males was examined for size and shape, while the number, shape and serrations of the blades making up the ovipositor of females were examined.

\section{DNA extraction}

DNA was extracted from the remains of the same insect individuals as had been identified morphologically and putatively classified as male, female or nymph members of M. fuscovaria. A number of individual specimens of each of the different classes was extracted to assess inter-specific variation of the coxl gene sequence.

Total DNA was extracted from individual insect specimens following a slightly modified version of the CTAB extraction method described by Doyle and Doyle (1990). The insect remains were macerated with a micro-pestle in microtubes containing $200 \mu \mathrm{l}$ of $2 \%$ CTAB with freshly added
$0.2 \%$ mercaptoethanol. Following this, a further $200 \mu \mathrm{l}$ of $2 \%$ CTAB with $0.2 \%$ mercaptoethanol was added, and the mixture was incubated at $65^{\circ} \mathrm{C}$ for 30 min whilst shaking. An equal volume $(400 \mu \mathrm{l})$ of chloroform was added and gently mixed in, after which the mixture was centrifuged for 10 $\mathrm{min}$ at $11000 \mathrm{~g}$. The supernatant was recovered and again treated with chloroform as above. The supernatant was then treated with an equal volume of isoamyl alcohol. Tubes were centrifuged at $12000 \mathrm{~g}$ for $30 \mathrm{~min}$ at $10^{\circ} \mathrm{C}$. The supernatant was discarded and $1 \mathrm{ml}$ of $70 \%$ ethanol was added to the pellet and mixed, and the tubes were centrifuged at $12000 \mathrm{~g}$ for $10 \mathrm{~min}$ at $4^{\circ} \mathrm{C}$. The supernatant was discarded and the washing step was repeated if needed. After the final washing step, samples were left to air dry for $20 \mathrm{~min}$. Pellets were resuspended in $50 \mu \mathrm{TE}$ buffer and stored at $-80^{\circ} \mathrm{C}$.

\section{PCR}

Mitochondrial coxl genes were amplified using the primers described by Folmer et al. (1994) (LCO1490: 5'-ggtcaacaaatcataaagatattgg-3' and HC02198: 5'-taaacttcagggtgaccaaaaaatca-3'). Insect DNA extract $(1 \mu \mathrm{l})$ was added to a final PCR reaction volume of $50 \mu \mathrm{l}$, consisting of $25 \mu \mathrm{l} 2 \mathrm{X}$ Dream Taq Green PCR mastermix (ThermoScientific, Waltham, MA, USA), $5 \mu \mathrm{l}$ of a $10 \mu \mathrm{M}$ solution of each primer, and $15 \mu \mathrm{l}$ molecular grade O (SigmaAldrich, St. Louis, MO, USA). A PCR cycling reaction was performed on a T100 ${ }^{\mathrm{TM}}$ Thermal Cycler (Bio-Rad, CA, USA). Cycling conditions were set up as follows: initial denaturation at $94^{\circ} \mathrm{C}$ for $4 \mathrm{~min}$, followed by 35 cycles of denaturation at $92^{\circ} \mathrm{C}$ for $60 \mathrm{~s}$, annealing at $52^{\circ} \mathrm{C}$ for $60 \mathrm{~s}$ and elongation at $72^{\circ} \mathrm{C}$ for $90 \mathrm{~s}$, with a final elongation step at $72^{\circ} \mathrm{C}$ for $10 \mathrm{~min}$.

\section{Sequencing}

To remove single-stranded DNA from the PCR products, $0.5 \mu \mathrm{l}$ of $10 \mathrm{U}$ exonuclease (Fermentas, MD, USA) and $2 \mu \mathrm{l}$ of $2 \mathrm{U}$ FastAP $\AA$ (Fermentas, MD, USA) were added to the amplification products and the reaction was carried out as per the manufacturer's instructions. Purified amplicons were sequenced in both orientations using the individual Folmer et al. (1994) primers in a PCR reaction using Big Dye $\mathbb{R}$ Terminator v 3.1 cycle-sequencing kit (Applied Biosystems, Foster City, CA, USA) as per manufacturer's instructions. Sequences of amplicon products were determined using an ABI 3500xL automated sequencer (Applied Biosystems, Foster City, CA, USA) at the core sequencing facility of the University of Pretoria, South Africa.

\section{Sequence analysis}

Forward and reverse sequences were aligned and consensus sequences were obtained using CLC Main Workbench (CLC, Aarhus, Denmark). Sequences were subjected to multiple alignments with CLC workbench and maximum likelihood dendrograms were constructed in MEGA software version 6 (Tamura et al., 2011), with 1000 replicates of bootstrap analysis.

\section{RESULTS AND DISCUSSION}

In total, 50 males, 35 females and a number of nymphs of the two species of Mgenia were examined and the individual 
remains were placed in individual labelled tubes for DNA extraction and PCR. The males of M. fuscovaria were shown to have a large, blade-like sex organ, while in M. angusta the sex organ is small and needle-like. Females were examined in a similar manner. At high magnification of the three pairs of blades that make up the ovipositor, the valvula 2 had a row of 10 to 12 teeth in M. fuscovaria, while M. angusta, also found in grapevines (A. de Klerk, unpublished data), had eight to nine teeth. No differences were found in the colour or shape of the body, or wing veins, amongst the individuals monitored. Nymphs could not be assigned to a species using morphological traits.

The sequence of cox 1 from representative M. fuscovaria male specimen 13-0076 was deposited in Genbank with accession number KP823217. The coxl sequence of putative $M$. fuscovaria nymphs (collected at the same locality where and on the occasion when the M. fuscovaria adults were collected) was identical to that of M. fuscovaria males. No $M$. fuscovaria females were sequenced.

The coxl nucleotide sequence of $M$. angusta was determined using nine male and four female specimens.
The sequence of a representative $M$. angusta specimen (125157) was deposited with Genbank with accession number KP823218. The sequence could be used to differentiate M. fuscovaria and M. angusta individuals (Fig. 1).

Morphological differentiation of the two species of Mgenia was perfectly correlated with the sequence differences observed in all identified M. fuscovaria and all $M$. angusta specimens separating into two distinct clades, with no exceptions (Fig. 1). Small sequence differences amongst individual specimens of a given species were primarily due to ambiguous bases between the forward and reverse sequencing reactions, and were generally not present in any other individual.

\section{CONCLUSIONS}

The mitochondrial coxl gene sequence of Mgenia fuscovaria, as well as that of Mgenia angusta, a related grapevine-associated leafhopper, has been determined. These sequences differ sufficiently that species identification can be based on the sequence of the coxl sequence of the two species. While genes from M. fuscovaria females were

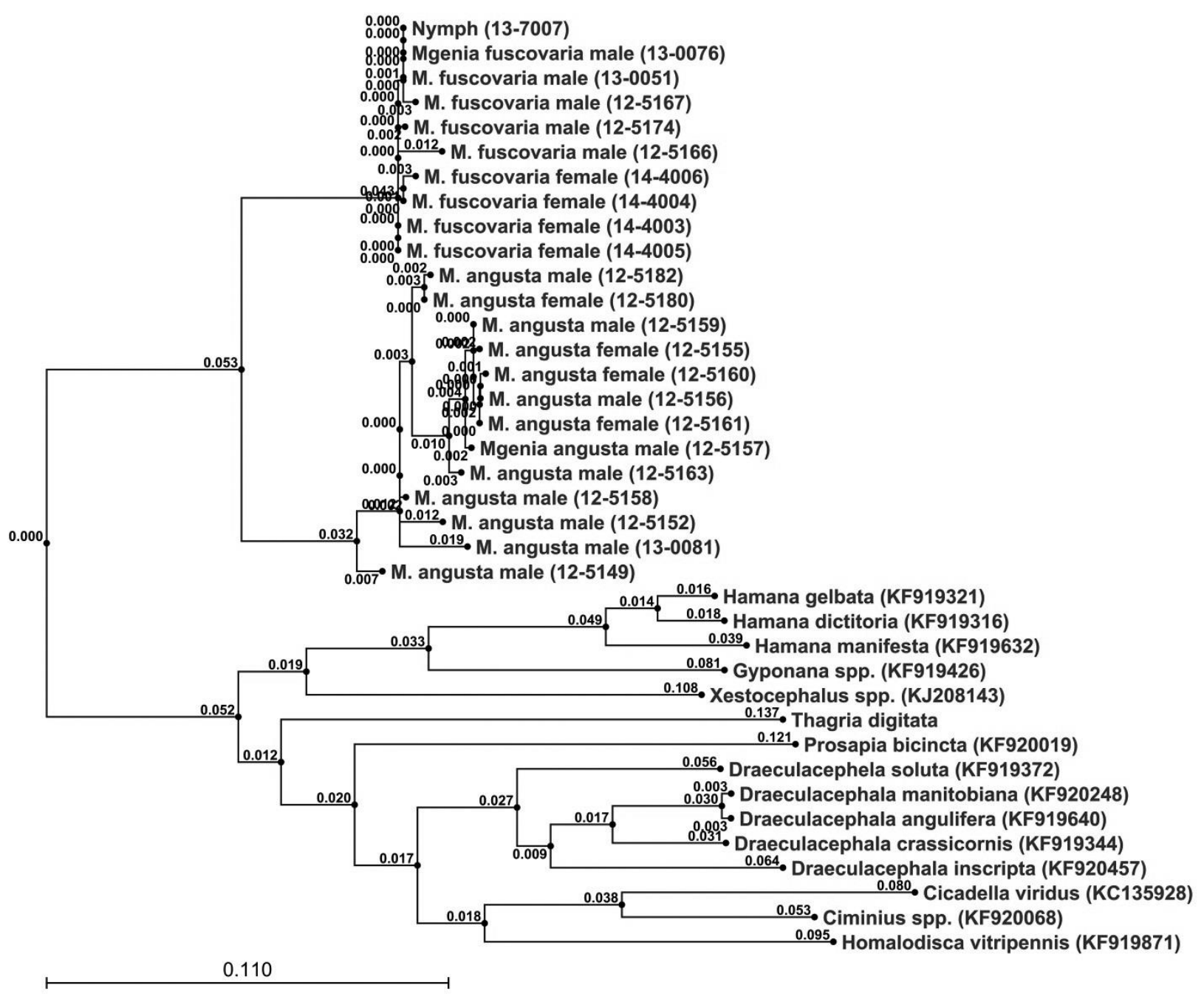

FIGURE 1

Maximum likelihood phylogenetic tree of the mitochondrial cytochrome oxidase subunit 1 gene (coxl) of Mgenia fuscovaria, M. angusta and the closest leafhopper sequences currently available on Genbank (as determined by BLAST analysis). Tree produced by UPGMA program, Jukes Cantor substitution model. 
not sequenced, identity within $M$. fuscovaria males and nymphs, and $M$. angusta males and females, suggest that the sequences generated can be used to identify $M$. fuscovaria and $M$. angusta males, females and nymphs. Differences in sequence were insufficient to develop species-specific PCRs. However, we have achieved the objective of using sequence data to help identify specimens of both species, especially nymphs, for further AY insect-transmission studies.

\section{LITERATURE CITED}

Doyle, J.J. \& Doyle, J.L., 1990. Isolation of plant DNA from fresh tissue. Focus 12, 13-15.

Engelbrecht, M., Joubert J. \& Burger, J.T., 2010. First report of aster yellows phytoplasma in grapevines in South Africa. Plant Dis. 94, 373

Folmer, O., Black, M., Hoeh, W., Lutz, R. \& Vrijenhoek, R., 1994. DNA primers for amplification of mitochondrial cytochrome $\mathrm{C}$ oxidase subunit I from diverse metazoan invertebrates. Mol. Mat. Biol. Biotechnol. 3, 294 299.
Hebert, P.D.N., Cywinska, A., Ball, S.L. \& deWaard, J.R., 2003. Biological identifications through DNA barcodes. Proc. Royal Soc. Lond. 270, 313 321.

Krüger, K., De Klerk, A., Douglas-Smit, N., Joubert, J., Pietersen, G. \& Stiller, M., 2011. Aster yellows phytoplasma in grapevines: Identification of vectors in South Africa. Bull. Insectol. 64, S137-S138.

Nault, L.R. \& Rodriguez, J. G., 1985. The leafhoppers and planthoppers. John Wiley \& Sons, New York.

Papadopoulou, A., Bergsten, J., Fujisawa, T., Monaghan, M.T., Barraclough, T.G. \& Vogler, A.P., 2008. Speciation and DNA barcodes: Testing the effects of dispersal on the formation of discrete sequence clusters. Philos. Trans. R. Soc. Lond. B. Biol. Sci. 363, 2987-2996.

Tamura, K., Peterson, D., Peterson, N., Stecher, G., Nei, M. \& Kumar, S., 2011. MEGA5: Molecular evolutionary genetics analysis using maximum likelihood, evolutionary distance, and maximum parsimony methods. Mol. Biol. Evol. 28, 2371-2739.

Theron, J.G., 1984. Coelidiinae (Hemiptera: Cicadellidae) described from South Africa in the genera Palicus Stål, Equeefa Distant and Aletta Metcalf, with descriptions of new species. J. Ent. Soc. S. Afr. 47, 313-327. 